\title{
Lateinische Beispielsammlung mit Bildern.
}

Von dem Inhalte der Handschrift 390 der Hamilton'schen, jetzt der Kgl. Bibliothek zu Berlin gehörenden Sammlung bleibt, nachdem ich aus derselben die Übersetzung des Dionysius Cato (1883), das Buch des Uguçon da Laodho (I 884), das Spruchgedicht des Girard Pateg (1886) in den Abhandlungen der Kgl. Preufsischen Akademie der Wissenschaften, die Proverbia super Natura feminarum (1885) und die Weinende Hündin (1886) in der Zeitschr. f. rom. Phil. Bd. IX und X, endlich die Übersetzung des Pamphilus (r887) im Arch. glott. herausgegeben habe (als Anhang zu je einem der ersten drei Stücke auch noch ein lateinisches Buchstabenorakel, lateinische Verse über die vier Temperamente und eine italienische Paraphrase des Paternoster), nur noch der Inhalt der Blätter 27 bis 49 übrig. Ihn bringen die nachfolgenden Seiten. Recht verschiedenartige Dinge sind hier zusammengestellt; zu einer gewissen Einheit sind sie aber durch den verbunden, der die Handschrift hat ausführen lassen: die gleiche sorgfältige Schrift herrscht von Anfang bis zu Ende, bemalte Zeichnungen einer und derselben Hand begleiten den Text, und zwar hier nicht am Rande eingetragen, wie in den übrigen Teilen der Handschrift, sondern die ganze für die Schrift in Anspruch genommene Breite des Raumes ausfüllend; und auch dem Inhalte nach besteht insofern doch eine gewisse Verwandtschaft der Bestandteile, als das, was an Mitteilungen aus dem Tierleben oder an Geschichten von Tieren und von Menschen dargeboten wird, eine Nutzanwendung für menschliches Leben erfährt, Gedanken heilsamer Natur zwischen hinein auch ohne derartige Anknüpfung vorgetragen oder an die Vorstellung dieses oder jenes Dinges angehängt werden, davon ein Bild darüber steht. Ein Bilderbuch mit Text, darin man zu seiner Erbauung blättern und lesen mag, noch eher als eine blofse „Beispielsammlung" für den Prediger, der seiner Ermahnung und Belehrung veranschaulichende Geschichten und Bilder einzuflechten für ratsam hält; denn was sollten diesem die Bilder? Am Schlusse fügen sich drei Stücke an, die den zugehörigen Bilderschmuck wieder wie die übrigen Stücke der Handschrift am Rande mitbekommen haben und schon dadurch als etwas blofs zufällig hier Untergebrachtes kenntlich würden, wenn sie nicht auch dem Inhalte nach aufserhalb der Gemeinschaft. stünden z." der die vorkergehenden 
Stücke sich verbinden. Die folgenden Zeilen sollen in das Durcheinander der Zusammenstellung eine gewisse Ordnung bringen und das Auffinden der einzelnen Stücke, die ich im Abdrucke beziffert habe, erleichtern. Am Schlusse ist über Orte, wo man gleichen Stoff wieder findet, einiges beigebracht.

Eirten bedeutenden Bestandteil bilden die Angaben über merkwürdige Eigenheiten verschiedener Tiere: die Spinne I, der Adler 2, die Schlange 3, die Ameise 4, der Hirsch 5, die Sirenen 6, der Elefant 7, der Panther 8, das Rebhuhn 23, die Schlange (aspis) 25, der Straufs 26, die Turteltaube 27, der Rabe 36. Ein vollständiger Physiologus ist, wie man sieht, nicht aufgenommen; Löwe, Einhorn, Hydra, Affe, Fuchs und andere im Physiologus nie übergangene Tiere haben eine Stelle nicht gefunden. Was über die hier behandelten Tiere vorgetragen wird, ist auch nicht ausschliefslich das, was die alten Bestiarien davon lehren, sondern fliefst teilweise aus andern Quellen.

Weiter finden wir eine Anzahl Tierfabeln: Fischchen, das vergeblich bittet freigelassen zu werden, bis es grölser sei, 10; Stiere, die vereinzelt sich des Löwen nicht mehr erwehren, I I; Baum und Schilf im Sturm, I2; Ziege lälst sich nicht vom Wolfe in die Tiefe locken, 13; Kärrner, der um himmlische Hülfe fleht statt selbst Hand anzulegen, 14; Ameise und Grille, 15; Löwe soll sich mit Ziege, Schaf und Kuh in die gemeinsame Beute teilen, diese gehen leer aus, 19; der lügnerische Räuber und der Löve, 39; Frosch, der sich bläht, 40; Katze erspart der Maus alle Sorge um die Zukunft, 4I; Ratte vom Frosch zur Wasserfahrt verlockt, 42 ; Fuchs vom Hirsch für Hohn gezüchtigt, 43; hochmütiges Pferd spottet des magern, wird aber selbst Gegenstand des Mitleids, 44. Unter diesen Fabeln sind manche, die sich aus Avian und aus Romulus weit verbreitet haben, ein paar aber auch, die sonst kaum begegnen, freilich nicht die besten.

Auch Legenden sind der Sammlung einverleibt: vom Einsiedel, der die Finger ins Feuer steckt, um einen Vorschmack der Hölle zu bekommen, und damit sich der Versuchung erwehrt, i6; vom Einsiedel, der um der Tochter des Götzenpriesters willen den Glauben abschwört, I 7; von dem, der aufgehört hatte, seinen Erwerb den Armen zu geben, 18; von zweien Mönchen, deren einer sich fleischlich verging, worauf der andere, gleiche Schuld vorgebend, die Bufse mit ihm auf sich nahm, 24. Diese Stücke stammmen sämtlich aus den „Leben der Väter".

$\mathrm{Zu}$ einer besonderen Gruppe darf man vereinigen die Deutungen einzelner sinnlich wahrnehmbarer Dinge auf sittliche oder religiöse Verhältnisse : Erde, 20; Himmel, 21; Meer, 22 ; Schiff (unfertig), 28; Berge und Thäler, 29; Mond, 37; Sonne, 38.

Es bleiben noch die kurzen Betrachtungen über menschliche Lebensverhältnisse, christliche Pflichten, u. dgl.: Freunde und Ärzte in der Not bewährt, 9; das Böse hassenswert, nicht der es thut, 30; Sündenfall, 31; Zustände der erlösten und der verdammten 
Auferstandenen, 32; Wandel des Bischofs und des Predigers, Betrachtungen über den Hochmut als Begleiter der Sünde, 33; falsches Zeugnis, 34 ; ungerechte Richter, 35.

Die drei angebängten Stücke enthalten: a) diätetische Vorschriften für jeden Monat des Jahres; b) Mittel gegen Blasensteine, gegen Schlaflosigkeit, gegen Fieber; c) Anleitung Träume mit Hülfe des Buchstabenorakels zu deuten.

Der Text wird hier mit allen den argen grammatischen Fehlern abgedruckt, die er in der Handschrift aufweist; wollte man hier einmal $\mathrm{zu}$ bessern anfangen, würde man nur schwer bestimmen können, wo damit aufzuhören sei. Was gesagt werden soll, zu erkenuen hindern die vielen Schnitzer nicht. In eckigen Klammern sind Buchstaben eingeschaltet, die einmal dagewesen sein werden an Stellen, wo das dünne Pergament jetzt Löcher zeigt. In schräger Schrift lasse ich drucken, was ich an die Stelle von Abkürzungen setzc. Fehler, die unzweifelhaft nicht auf Unvermögen des Schriftstellers, sondern auf Nachlässigkeit des Schreibers zurückgehen, verbessere ich in den Anmerkungen unter dem Texte.

\section{I.}

$\left(27 r^{\circ}\right)$ Oben in der Mitte des Blattes eine Spinne in ihrem Netze, auf jeder Seite eine Fliege (. araneus . musca).

Raneus est uermis paruus . qui facit recia et in illa recia aprehendit muscas. Set cum erit aliquis uentus leuiter runpitur: Significat homines qui suos fideles decipiunt. set mors cito uenit et occidit eos . et miseri uadunt in infernum:

2.

In der Mitte eine rote Sonne (mit menschlichen Zügen); links fliegt ihr ein blauer Adler (. aquila.) zu, rechts fliegt ein Adler einem eckigen Brunnentrog (. fontana .) zu; in der Mitte unter der Sonne abermals ein Adler, dieser stehend.

Quila est uolucris que quando est uetula uolat super fontem tan-
tum quod sit uicina celo . el calor solis ardet alas suas . et cum
ale sunt arse illa uadit ad fontem . et sumergit se ter in fon-
tem . ct uenit ita iuuenis . quasi exierit anido: Significat ominem.
qui quando est ter mersus in babtismate. leuat se mundatum ab
omni peccato:

3.

Eine rötliche Schlange, die sich, in Stücken sichtbar, durch etwas hindurchwindet (. serpens que renouat se .); daneben eine bläuliche Schlange mit Füfsen und geringeltem Schweif.

a) Erpens quando uetus est . sic renouatur ut iam audietis. Jeiu$D$ nat tam diu quam sua $\left(27 \mathrm{v}^{0}\right)$ pellis tremit . et nichil remanet W. I sibi nisi osa et nerui. Tunc querit strictum foramen petre et transeundo spoliat se de ueteri pelle et uix ualens transire per foramen petre: b) Similiter habet et aliam naturam - quando uenit ad aquam ut bibat. iactans ase totum uenenum quod in se habet. et 
propter hoc aliquod malum non facit in aqua: c) Fr aliam naturam habet si uidet hominem sine ueste . fugit ab eo sicut fugeret $a b$ igne: Ft quando uidet hominem uestitum . cito uadit ad eum .d) et si homo uincit illum et multum persequitur . habet suum corpus in neglegencia: a) Quod serpens ueterata renouatur . quando renouatur multum ic runando ${ }^{1}$. intra strictum foramen petre . et ibi perdit pelem suam: Significat hominem peccatorem in suis peccatis tam diu permanentem . et multum afligendo corpus suum in ieiuniis. elemosinis . oracionibus . quod misericordiam consequitur . et sic peruenit ad cristum et fit nouus homo . sicuti est quando exit de babtismo . et inuenit uitam eternam .b) Ft sicut serpens quando uenit ad aquam et statim bibit . sed ante quam bibat euomit totum uenenum quod habet inse. sic debet homo facere quando uenit ad eclesiam . ut manducet corpus domini . ante debet iactare ase totum uenenum hoc est superbia . ira . hodium . inuidia . iracundia et $\left(28 \mathrm{r}^{0}\right)$ cetera uicia: c) Ft sicut serpens fugit hominem nudum . sic diabolus fugit hominem nudum apeccato . et non appropinquat eum.

4.

Zwei Ameisen (. formica .) zu beiden Seiten von Ähren. Ein Mann mit grauem Haar und Bart mit lehrend erhobener Linken. Ein Knieender (. iste recipit legem) empfängt aus der Rechten eines stehenden Christus (.xp̄s qui dat legem hominibus.) ein Buch.

a) Ormica non cessat portare granum in estate unde uiuat in yeme . quia si non laboraret in estate moreretur in yeme: et hoc timet . unde tantum laborat in estate . quod suficit sibi in yeme. b) et si inuenit ordeum refutat illum: Sic omnis homo tantum tantum ${ }^{2}$ laborare debet in hoc seculo . quod habeat in die iudicii uitam eternam. Quod si non laborauerit quamdiu est in hoc seculo . post quam ueniet ad iudicium . et ${ }^{3}$ non poterit laborare et morietur: Et sicut formica non tollit ordeum . sic omnis homo non debet tenere ueterem legem . sicut 4 medula significat ueterem legem . sic $^{5}$ medula ordei est absconsa inter paleam. sic antiqua lex est absconsa et tota figurata: -Sed quando dominus noster iesus cristus uenit in istum mundum. suscipere carnem humanam pro peccatis nostris . tota lex que ante erat absconsa est manifesta et aperta :

5 .

(28 v0) Ein Hirsch den Kopf senkend nach zwei Schlangen (ceruus qui maducat . serpente .); ein Hirsch trinkend, darüber zwei Männer zusammen wandelnd. Zwei Hirsche schwimmen durch Gewässer, des hinteren Kopf liegt auf des vorderen Kreuz (cerui qui natant).

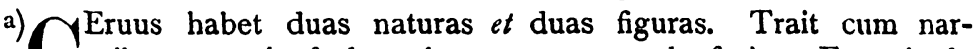
ribus superius ${ }^{6}$ de subtus terra aut de foris. Et trait de foramine petre . magnos serpentes . et manducat illos . uene-

1 L. ueterata renouatur multum iei unando.

2 Ein tantum zu tilgen.

s Zu tilgen? $\quad$ \& $Z u$ tilgen. 5 Lies sicut. $\quad$ ' $L$. serpentes 
num autem serpencium . bulit in uentre eius. Tunc uadit ceruus ille cum magno desiderio ad fontem aque . et bibit multum . et sic. uincit uenenum. Sic nos quando super habundat odium . aut ira . uel aliquod aliud uicium . debemus currere ad fontem uiuum . hoc est cristum . qui per suam magnam misericordiam infudit ${ }^{1}$ in nobis spiritum santum . et efugat luxuriam . odium et iram aut auariciam . et omnia mala uicia . que in nobis sunt . et nos peccare cotidie faciunt: b) Et aliam naturam habet ceruus . quando natat cum aliis ceruis ultra fluuium . in ordine natat.et unus tenet mentum in dorso alterius si esset ${ }^{2}$ centum aut plus senper sic natant .et cum ille ceruus qui uadit antea est fatigatus .postea uadit retro. Et stat apodiatus supra dorsum alterius . sic faciunt quando uadunt longe ad pascua . et proter hoc nunquam fatigantur. Sic unusquisque cristianus si uult ire ad pascua cristi hoc est ad (29r0) uitam eternam . debet portare pondus alterius sicut dicit apostolus. Alter alterius onera portate et sic adimplebitis legem cristi.

6.

Neun Sirenen, die weiblichen Oberleiber ragen aus der grünen Flut, welche die Fischschwänze erkennen läfst (. sirene.); auf dem ihnen zugewandten Hinterteil eines Schiffes mit Segeln und Rudern werden die Häupter zweier Schiffer sichtbar (nauis .).

QIrene sunt monstra maris . que ab umbilico sunt facte quomodo $\$$ uirgo . et de subtus sunt in similitudine piscis . et cantant sic dulciter . quod nautes uadunt ad illas . et pre nimia dulcedine cantus dormiunt aut ${ }^{3}$ ronpontur naues . aut ${ }^{3}$ nulatenus possunt euadere nautes et ita pereunt: Quod sirene habent diuersas formas . significant homines . qui aliud abet 4 in corde et aliud in ore: Ft sicut sirene pro nimia dulcedine cantus sui trahunt ad se nautes. et faciunt illos dormire et perire . sic multi homines decipiunt alios. cum suis dulcibus dictis. Multi sunt qui benedicunt et sante precipiunt aliis . et sunt maliciosi interius . sicuti multi presbiteri et episcopi . qui bene dicunt . et senper predicant alios . et intus sunt pleni de malis peccatis. Omnis ${ }^{3}$ enim qui ueri sunt presbiteri . secundum quod eorum santi patres constitue[r]unt . uere abent in se spiritum santum: Ft quam uis non faciant signa (29v0) corporaliter sicut faciebant apostoli . $\operatorname{tunc}^{6}$ spiritualiter faciunt signa - per spiritum santum . quia cecos illuminat $i$ demones fugant: Certe infans qui nascitur . cecus est . et demones abet in se . septem. Cecus est quia in tenebris nascitur. et non abet lumen fidei . sicut apostolus dicit. Populus gencium qui ambulabat in tenebris . uidit lucem magnam et cetera: Hoc dixi uobis quia nos sumus cristiani . et non cognoscebamus uiam ueritatis . ante quam fuissemus cristiani
$1 L$. infundit.
1 $L$ : abent.
$2 L$ essent.
8 L. et.
7 L. illuminant.
5 L. omnes.
6 $L$. tamen.


. sed eramus in peccatis et quasi in morte - quando nos non adorabamus creatorem. sed creaturam . et propter hoc omnis homo quando nascitur cecus est . et est in potestate diaboli . propter peccatum nostri primi parentis . id est adam . quia deus quando fecit adam . fecit eum inmortalem . ut non moreretur. set senper uiueret . et omnes qui nasceretur ${ }^{1}$ ab illo . et non deberet laborare . nec infirmitatem abere . sed senper uiueret in magnis deliciis: Sed quia adam peccauit expulit eum deus ase de paradiso uoluptatis . in quo posuerat eum deus propter inobedienciam et superbiam suam . quia quando deus posuit adam in paradiso . precepit ei ut de omni pomo comederet nisi de uno. sed ille per sugestionem diaboli de intradic[to p]omo comedit: Ft propter hoc iactauit eum deus de para- $\left(3^{\circ} \mathrm{r}^{0}\right)$ disso et dixit ad eum ${ }^{2}$ et propter hoc non tantum ille. sed omnes qui nati sunt de illo . cum sudore uultus sui et magno dolore uiuunt in hoc mundo:

\section{7.}

Ein Elefant seitwärts an einen Baum gelehnt, ein zweiter auf dem Rücken liegend zwischen den $z$ wei Teilen eines abgebrochenen Baumes; ihn sucht ein dritter kleinerer mittels der langen Zähne aufzurichten (. elefantes .). Einem vierten, der im Wasser steht, kriecht ein kleiner aus dem Bauche. Ein

knieender Alter hebt die Hand zu Christo empor, der ihm die Rechte

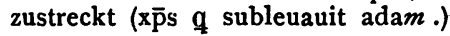

a) lèfantes sunt bestie grandes quasi montes . que dum uadunt 1 ad pascua insimul uadunt . quasi peccora . b) et quando masculus concubit ${ }^{3}$ cum femina retrouersi conueniunt.c) per multum tempus uiuunt. et quam uis per trecentos annos uiuant . nunquam faciunt filium nisi semel.d) et unquam non infirmantur nisi quando moriuntur. e) Egenuerant 4 unum filium . et portant duos annos . et quando elefans uenit ad tenpus parturiendi . intrat in magnam aquam . et ibi facit filium suum. ne cadat in terram . quia si caderet in terra statim moreretur. f)Et elefans nunquam flent $^{5}$ genua - quia si caderet nunquam releuaret. sed quando uult dormire aut quiescere . apodiat se ad arborem - postea uenit ad arborem uenator et secat illam arborem apud quam elefantem est solitus dormire. postea elefantem uenit ad eandem arborem . et apodiat sc. sicut solebat . et arbor statim cadit et elefantem cum eo. g) Er si homo non est ibi tunc mitit uocem magnam. et ad illam uocem unus de aliis elefantis currit . $\left(30 v^{0}\right)$ et uult releuare eum sed non potest . et cum non potest mitit magnam uocem ad quam multi alii grandes conueniunt . et omnes uolunt releuare eum sed non possunt . et cum uolunt eum releuare $e t$ non possunt . tunc omnes clamant et ad uoces illor $u m$ ueniunt parui et magni . tunc parui leuat 6

\footnotetext{
1 L. nascerentur.

2 Hier ist übersprungen cum sudore vultus u. s. w.

3 L. concumbit.

6 $L$. leuant.

$1 L$. Et generant.

5 L. flectit.
} 
illum et est magnum miraculum . et sic fugit insidias uenatoris. h) Et pili sui habent hanc naturam . quod si ardes illos fumus qui exit de pillis fugabit serpentes . et quicquid abet uenenum: Quod elefans cadit significat adam primum hominem qui per pomum de arbore quod manducauit cecidit in infernum et in peccatum . postea uenit moyses profeta . et non potuit eum liberare: Post moises uenerunt profete et uoluerunt liberare eum et non potuerunt. Postea uenit cristus qui per preces illorum suscepit carnem humanam . et liberauit omnes homines apeccato nostri primi parentis: Quod fumus de pillis elefantis fugat serpentes. significat santam scripturam . de qua quicunque est bene plenus. omne peccatum fugit ab illo pro cristo:

8.

Ein Panther (pantera .); abermals ein Panther, ihm gegenüberstehend etwas, was mir ein dreiköpfiges Tier vorn mit vier, hinten mit zwei Beinen scheint (bestie que curunt ad eam); drei Männer vor Christo (.xp̄s.).

a) Anthera est bestia multum pulcra . et est nigra $\left(3 \operatorname{Ir}{ }^{0}\right)$ et habet albas maculas . et passit se de aliis bestiis .b) et quando est bene saturata uadit in absconsum locum . et dormit per tres dies. et in tercia die leuat se . et multum rugit.c) sed talis odor exit de guture eius quod est maior quod non eset ille de omnibus speciebus huius mundi et proter illum hodorem omnes bestie curunt ad eam .d) preter dracones qui fugiunt aut abscondunt se subtus terra . nec apparet 1 in illo tenpore: a) Panthera significat cristum . qui fuit splendidus plusquam alii homines . et omnes homines ad se trait quos ipse uult: b) Et sicut pantera post quam saturata est per tres dies iacet. sic cristus per tres dies iacuit in sepulcro. et post tercium diem leuauit se de sepulcro .c) $\mathrm{E}^{2}$ sicut alie bestie currunt ad pantheram quando leuat a sompno . sic quando cristus leuauit de sepulcro . omnes gentes uenerunt ad eum et crediderunt in eum .d) Et sicut dracones abscondunt se quando pantera leuat asompno.sic diabolus fugit et abscondit se.postquam cristus surexit de sepulcro:

9.

Mann am Stabe in gebückter Haltung; Leute, die sich von ihm abwenden; Mann (. pauper), der aus den Händen eines anderen ein Gewand empfängt (iste dat suam tunica pauperi); ein Mann kniet vor dem thronenden Christus (. xpss.).

Micus in necessitate . et medicus in infirmitate . hii duo apertissime conprobantur. Hoc est quod quando abes necessitatem potes probare $\left(3 \mathrm{Iv}^{0}\right)$ amicum tuum . quia ille est bonus amicus qui adiuuat te in tali necessitate in qua omnes alii qui erant tuos amicos te abent bandonatum. Similiter ille est bonus medicus
1 L. apparent.
2 L. Et. 
qui liberat te de tali infirmitate . de qua omnes alii medici te mortuum dereliquerunt.

IO.

Mann am Wasser, einen an der Angel hängenden Fisch in der Hand (piscator). Ein Mann streckt die Hand nach einem sitzenden Manne, der mit der Linken einen grofsen Becher von einem Tische nimmt.

$\mathbf{U}^{N}$

Nus piscator piscabat cum amo . et aprehendit paruum piscem . et cum piscator accipiebat eum dixit piscis ad piscatorem. $\mathrm{O}$ piscator ego precor te ut dimitas me . quia nimis paruus sum modo . sed iecta me in aquam . et quando ero grandis . tunc abebis maiorem precium de me. Tunc dixit piscator ad eum . certe non dimitam te. hoc significat . quia stultus est ille homo qui quando abet aliquam rem in sua potestate . et ${ }^{1}$ dat illam alteri. Istud quod est dictum de piscatore et de pisce. non est dictum ideo quod fuisset uerum . sed dictum est propter exemplum . et castigacionem - quia nulus homo abens aliquid in sua potestate . non debet dare id quod est alicui . quam uis ut ${ }^{1}$ ille diceret ei tu eris ita securus ut si tu aberes ipsam in te quia sepe accidit quod illi qui dant res suas aliis . non posunt eas recuperare sic cito ut uolunt. Sicut piscator si dimisiset $\left(32 \mathrm{r}^{0}\right)$ pissem paruum . non abuisset postea illum magnum neque paruum . quia melius fuit $e t$ est abere paruum quam extoto nichil.

\section{I.}

Zwei Stiere (. tauri .) rennen auf einen am Boden liegenden Löwen (. leo.) zu. Löwe steht auf einem an der Erde liegenden Stier, in dessen Nacken er beifst (leo comedit taurum); rechts und links läuft je ein einzelner Stier.

$\mathbf{Q}$ uatuor grandes $e t$ fortes tauri iurauerunt simul quod unquam non diuiderent se et postquam iurauerunt senper ibant simul in omni loco . et in quacumque ${ }^{2}$ loco ipsi pergebant nec lupus nec aliam feram timebant . set eciam leo timebat eos. Set postquam fuerunt separati et unus ibat sine alio. leo inuenit unum de ilis solus . et occidit eum et comedit. Et post inuenit unum alium solum et comedit illum et sic fecit de omnibus . et comedit omnes quatuor tauros: Isti tauri significant illos homines . qui propter timorem quem abent de suis maioribus uel forcioribus . uadunt et stant simul . et quamdiu stant simul . eciam maiores timent eos . et non audent illis offendere. Set quando sunt separati.tunc ille maior paratus est ofendere eis . et faciunt illis multa mala. Fit propter hoc quando duo homines uel tres habent bellum cum suo maiori uel forciori . debent stare bene simul . et nunquam debent se separare uno ab alio . quia quamdiu stant bene $\left(32 \mathrm{v}^{n}\right)$ simul . non timent suum maiorem . imo maior timet eos et non uadit ${ }^{3}$ offendere eis . sed quando sunt separati et unus non adiuuat alium . tunc uenit suus maior et ofendit eis . el destruit eos de ramo aradice:
1 Zu tilgen?
2 L. quocumque.
3 L. audet. 
I 2.

Ein Baum schief stehend neben einem Berge; ein Baum im Wasser liegend (. arbor .); Schilfrohre teils stehend, teils gebeugt (cana.). Ein Mann mit gebeugtem Knie (homo humilis), die Hände erhebend zu einem mit Schild und

Schwert bewehrten Krieger (homo fortis).

Rbor erat in oriente in uno magno monte. multum grandis et A dura. 'Tunc exiit unus uentus ualde fortis . et cepit percutere illam set arbor nolebat se mouere. neque flectere. Et tunc uentus fuit iratus et cepit plus fortiter percutere eam. et tantum percussit eam . quod iactauit eam in flumine quod erat ad pedem montis. Tunc flumen duxit illam super canas. Et quando arbor uidit canas stare in pede fuit multum irata et dixit ad eas. Quare est hoc quod uos statis erecte . et uentus iactauit me que cram grandis et fortis . et uos non iactauit. Tunc cana respondit. te iactauit uentus proter hoc quot tu non plicas te. quando uentus uenit el propter hoc irascitur uentus et tamdiu percutit te quod iaclat te in terra. Set aqualicumque parte uentus uenit . ego flecto me . eciam si minimus uentus est . qua $\left(33^{0}\right)$ propter uentus non irascitur super me. Hoc quod dictum est de arbore et de canna non est dictum quod fuisset uerum . sed dictum est ad figuram et castigaciones nostras . arbor quam iactauit uentus in lerra propter hoc quod non flectebat se . significat illos homines qui proter suam superbiam nolunt credere 1 suo maiori . et forciori . et propter hoc paciuntur dedecus et uituperium . et plures sunt mortui: Et proter hoc omnis homo quando non potest contrastare suo maiori. debet se plicare sicut cana . que propter uentum siue magnum siue parum ${ }^{2}$ plicat se:

13.

Eine Ziege (capra) auf einem Berge, von dessen Fufse ein Wolf (lupus) zu ihr aufschaut. Aus einer Bergfestung ragen drei Krieger, deren einer eine Lanze nach drei Reitern am Fufse des Berges zückt.

T Na capra pascebat in uno alto monte . tunc uenit lupus ad pedem montis . et non poterat ascendere supra montem . tunc dixit ad capram. O capra . descende ad ualem istam.et pasce in isto loco . quia hic est bona herba. sed illuc ubi tu es non est ita bona. Tunc capra respondit et dixit.quam uis tu dicas uerum . quod melior erba sit ad pedem montis quam supra montem . tamen non descendam de monte . quia ego timeo ne occidas me et manducas. $\left(33 \mathrm{v}^{0}\right)$ Et sicut ${ }^{3}$ non potuit lupus tantum laudare herbam . quod capra descendiscet de monte . ubi stabat secura: Hoc quod dictum est de capra et de lupo . tamen non fuit uerum . set dictum est ad figuram et castigacionem nostram. Lupus significat illum hominem qui non potest alium aprehendere per suam uirtutem . et uult eum ducere ad locum ubi non sit securus et ubi poscit eum aprehendere. Set sicut capra non uoluit credere lupum. sic nos non debemus credere inimicis nostris qui uolunt nos ducere ubi nos non siamus securi:
$1 L$. cedere.
$2 L$. paruum.
${ }^{3} L$. sic.

Zeitsohr. f. rom. Phil. XII. 
I4.

Ein Mann schiebt am Hinterteil eines mit Ochsen bespannten Wagens (uilanus qui pingit carum); aus den Wolken ragt eine Hand mit ausgestrecktem zweitem und drittem Finger. Ein Nackter empfängt von einem reich Bekleideten ein Gewand; auch darüber eine Hand wie die beschriebene. Die Räder des Wagens und das zweite Wort des Textes fehlen, da die Farbe des Festungsberges im letzten Bilde das Pergament zerfressen hat.

$\mathbf{Q}$ Vidam [uilan]us ducebat carrum suum . et cum ipse duceret intrauit in magnam pissinam . tunc boues non poterant traere carrum foras . quia rusticus non pungebat boues nec mouebant' 1 se . et ipse precabatur deum ut adiuuaret carrum suum. Tunc uenit uox de celo et dixit ad eum. leua te $e t$ adiuua boues tuos. et punge illos . quia si non pungis boues tuos et non adiuuas eos. deus non exaudiet uoces nec preces tuas: Hoc dictum est quod omnis homo quando precatur deum ut adiuuet eum. $\left(34 \mathrm{r}^{0}\right) \times \times \times \times \times \times^{2}$ et se ipsum adiuare faciendo aliquod $X \times \times 2$ um. quia si laborauerit et orauerit . deus exaudiet preces eius:

\section{5.}

Baum, auf dem eine (grofse) Grille sitzt; eine Grille (cigala .), eine Ameise (. formica .). Ein Mann, die Rechte auf die Hüfte gestützt, die Linke wie bei einer Recitation ausgestreckt, daneben abermals eine Grille. Ein Mann knieend mit einer Axt in der erhobenen Rechten, einen Stab in der Linken; daneben eine Ameise.

Cicada uenit ad formicam in yeme el dixit ad eam . da michi de grano tuo . quia famem pacior. Tunc formica dixit ad cicadam . certe non dabo tibi . quia ego bene laboraui in estate et modo habeo quod possum manducare. Set tu tantum cantasti in estate . modo uade saltare quia de meo non portabis. Et cicada non potuit abere ullam causam de formicam: Hoc dictum est ad nostram castigacionem . cigada significat illum hominem quando debet laborare aut aliquod seruicium facere unde uiuat . et ipse iacet ad umbram et iocando uadit per plateas in yeme unde 3 non abet quod manducet et uadit mendicando et non potest inuenire quod comedat: FOrmica significat homines ${ }^{4}$ qui bene laborant ${ }^{5}$. quando est tempus laborandi . et postea bene uiuit de hoc quod laborauit in bono tenpore. Et propter hoc dixit salomon ad pigrum. Opiger uade ad formicam et ipsa te docebit quid debeas facere . hoc significat - quia homo debet laborare id est facere bona opera dum uiuit . unde ipse $\left(34 v^{0}\right)$ possit habere uitam eternam . que uita [eter]na nunquam finem abebit . quia omnes $g$ [au]debimus in magno gaudio:

1 L. mouebat.

2 Die innere obere Ecke des Blattes fehlt, und damit etwa sechs Buchstaben der ersten und drei der zweiten Zeile.

$3 \boldsymbol{L}$. unde in yeme.

4. 5 L. hominem .. . laborat. 
16.

Viermal eine Zelle mit einem auf Säulen ruhenden Dach; darin jedesmal vom Gürtel an sichtbar ein Mönch in blauer Kapuze (. monacus); in einiger Entfernung von der ersten Zelle ihr zugewandt ein Weib mit aufgelöstem Haar (femina que uult traere ipsum de monasterio.), hinter ihr etwas wie drei rote Hunde. Zu dem Mönch in der zweiten Zelle lehnt das aufsen stehende Weib sich über die Mauer hinein. In der dritten Zelle sind Mönch und Weib beide, davor ein rotes seltsames Wesen mit Flügeln. In der vierten schläft das Weib in sitzender Stellung den Kopf auf den Arm gelegt; drei Männer nähern sich der Zelle.

Q Vidam homo stabat solus in terra egypti religiosus et multum nominatus . et tota die sedebat in cella solus in loco deserto. Et ecce quedam mala femina audiens famam illius . dixit ad quosdam homines. Quid uultis michi dare et ego traham hominem illum de cella sua. Tunc homines promiserunt ei dare domum ${ }^{1}$. si posset eum trahere de cella sua. Tunc illa ornauit se bene . et uenit ad uesperum ad cellam suam quasi errasset et pulsauit . tunc monachus uenit ad eam et multum turbatus est propter eam et dixit ei. Quare uenisti ad cellam istam? Et illa respondit plorando et dixit ad eum. Ego erraui pater . tunc ille per misericordiam aperuit ei portam . et misit eam in quadam parte de cella sua . et clausit se interius in sua cella. Tunc cepit illa alta uoce clamare et dicere. $\mathrm{O}$ aliis ${ }^{2}$ miserere mei et adiuuate me ne peream . quia bestie me manducabunt in hac nocte. Ille autem $\left(35^{\circ}\right)$ dolens et timens dixit intra se. $\mathrm{O}$ deus unde uenit ista ira $^{3}$ ad me . et aperuit ei portam . et introduxit eam ase. Tunc diabolus cèpit stimulare cor illius et ardebat in amore femine . et cum ipse ita arderet . recordatus est quod diabolus faciebat eum sic ardere et dixit intra se . diabolus amat tenebras et obscuritatem . sed deus amat lucem et ueritatem. Et postquam dixit hoc . accendit lucernam et postea cepit orare cum magno desiderio de illa femina . tunc dixit in corde suo. Heu me illis ${ }^{4}$ qui faciunt talia uadunt ad tormenta.modo uolo probare inista nocte focum de ista lucerna . si potero sustinere. Et postquam hoc dixit . misit digitum suum in igne de lucerna, et conbussit digitum suum usque ad ossa et non senciebat propter nimium ${ }^{3}$ ardorem carnis quem habebat de illa femina et sic faciens usque in crastinum . et 6 arsit digitos suos. Tunc mulier uidens quod ille faciebat . propter nimium timorem mortua est. In crastino uenerunt homines ad monachum et dixerunt ei. Venit eri in sero femina in isto loco . et monachus respondit . sic fecit . ecce hic dormit . et intrantes inuenerunt ipsam mortuam . et dixerunt. Oabas mortua est. Tunc ille traxit manum suam de panno . et monstrauit eis digitos suos . qui erant toti arsi et dixit ad $\left(35^{\circ}\right)$. $\operatorname{ad}^{6}$ eos. Ecce quid fecit michi filia diaboli . per di $\times \times \times X^{7}$ meos. Et dixit èis quomodo illa ${ }^{8}$ dixit . fratres non debemus reddere

$1 L$. donum.

1 L. illi.

$2 L$. abas.

3 L. ita oder femina.

7 Loch im Pergamente.

8 Hier ist augenscheinlich mehreres verloren. 
malum pro malo. Et postquam hoc dixit adorauit ad dominum . et suscitauit illam. Qe postea conuersa est.et uixit in magna castitate.

I7.

Mönch in brauner Kulte (. monacus .); Mädchen begleitet von einem Mann in langem grünem Gewande (presbiter qui dat filiam sua ${ }^{1}$ monacho.); der Mönch im Gespräch mit dem grün Gekleideten. Der Mönch knieend vor einem weifsbärtigen Mönche, links von jedem ein Baum. Der greise Mönch betet, der junge steht daneben; aus einer Wolke ragt über ihnen eine Hand.

$7^{\text {Rat }}$ quidam monachus qui habebat magnum desiderium de 14 femina . et exiuit de monasterio et uenit in uicum vnum ${ }^{2}$ et uidit filiam unius presbiteri qui erat paganus . et adamauit eam . et dixit ad patrem suum. Da michi filiam tuam in uxorem. Presbiter respondit et dixit ad eum. Non possum tibi dare eam nisi antea dicam domino meo. Tunc presbiter iuit ad dominum suum et dixit ei. Est unus monachus qui uult accipere filiam meam . dic michi si uis quod dem eam sibi. Et respondens demon dixit. Si negat deum suum et babtismum et propositum monachi da ei filiam tuam. Tunc uenit presbiter ad monacum et dixit ei. Si negas deum tuum et babtismum et propositum monachalem . dabo tibi filiam meam. Et monachus concessit ei omnia que dicebat . et statim uidit quasi colunbam exire de ore suo $\left(36 \mathrm{r}^{0}\right)$ et uolare in celum. Tunc iuit presbiterus ad demo[nem] et clixit ei . ecce promisit facere ea que dixíst[i.et] respondit diabolus dixit ${ }^{3}$ ei. $\cdot$ Noli dare filiam tuam ei in uxorem . quia deus suus non recessit ab co.sed adhuc adiuuat eum. Tunc ueniens presbiter et ${ }^{4}$ dixit ad monachum . Non possum tibi dare filiam meam . quia deus tuus ad huc adiuuat te et non bandonauit te. Audiens hec monachus dixit infra se. Si tantam bonitatem fecit in me deus quem ego miser negaui . ergo multum bonus est deus meus . qui usque modo adiuuauit me . et si ipse non dimisit me . quare debeo recedere ab eo? Et intra se recordatus est abiit ad heremum ad unum magnum uetulum et religiosum et narrauit ei omnia que fecerat. Tunc respondit uetulus et dixit ad eum. Noli timere fili. sed sta mecum in spelunca mea inista nocte . et ieiuna tres dies et tres ebdomadas . et ego deprecabo deum prote . et laborauit uetulus pro fratre illo et adorauit ad deum dicens. Precor te deus misericors . qui non uis mortem peccatoris . set ut magis conuertatur et ujuat. dona ${ }^{5}$ hanc animam et suscipe oracionem meam et penitenciam istius fratris. Et exaudiuit deus oraciones illorum et quando conplecta fuit oracio de prima ebdomada - uenit uetulus ad illum fratrem et interrogauit illum dicens. Vidisti aliquid o frater? $\left(36 \mathrm{v}^{0}\right)$ Et [re]spondens dixit ad illum. Vidi colunbam . sursum in altitudinem celi supra capud meum. O frater dixit uetulus tibi metipsum atende. et precemur
1 L. suam.
4 Zu tilgen.
2 L. vicinum.
5 Lies etwa non bandona.
3 . et dixit. 
deum cum gemitu et planctu . et postquam uetulus dixit hec recessit. Et in secunda ebdomada reuersus est uetulus ad eum et dixit. $\mathrm{O}$ frater uidisti aliquid . respondit ille et dixit. Vidi colunbam super capud meum . et extendi manum manū 1 meam . et illa intrauit in sinu meo. Tunc gracias agens uetulus benedixit deum et dixit ad monachum. Ecce frater suscepit deus penitenciam tuam.amodo inantea noli peccare. Ecce modo tecum sum et ero pater tuus. et nunquam dimitam te nisi moriar. Hoc significat quando aliquis est in magna tribulacione. nos debemus succurere illum et dare ei adiutorium sicut fecit uetulus monacho et nos debemus sic succurre ${ }^{2}$ aliis in tribulacionibus suis:

18.

Mann legt etwas in die ausgestreckten Hände dreier vor ihm Knieenden (homo qui facit elemosinam). Ein Mann legt ein Geldstück in ein Büchschen. (hic abscondit pecuniam.). Ein Knieender beschäftigt sich mit dem rechten Fufse eines im Bette Liegenden (medicus qui medicat eum). Mann mit einem Käppchen (medicus). Mann mit Feldarbeit beschäftigt (homo qui laborat).

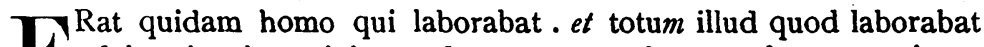
dabat in elemosinis; sed tantum tenebat quod posset uiuere et non plus. Sed postea misit diabolus in corde eius $\left(37 \mathrm{r}^{0}\right)$ dicens. Colige tibi aliquantulum de pecunia unde possis uiuere quando eris uetulus aut infirmus . et ipse colegit pecuniam tantum quod inpleuit uasunculum unum . sed postea infirmatum est multum in pede . et pes eius fiebat marcidus . et expendidit totum hoc quod habebat colectum in medicis . set nulum proficuum fecit ei. Postea uenit unus medicus et dixit illi $\mathrm{Si}$ non truncaueris tibi pedem totum corpus marcidum erit . et ordinauerunt diem quando debebant truncare pedem eius. Túnc ipsa nocte recordatus est homo ille et penitenciam faciens ingemuit et ait . cum lacrimis dicens. Recordare mei domine quando faciebam elemosinam . quando laborabam in orto . et ministrabam pauperibus de labore meo. Et postquam dixit uerba hec. uenit angelus domini et stetit apud illum et dixit illi. Vbi sunt denarios quos adunasti . et in quibus spem habebas . quod $^{3}$ inteligens dixil ad eum - peccaui domine miserere mei et nunquam faciam . tunc angnelus domini tetigit pedem eius . et statim sanus factus est . et leuans se in mane abiit operari . tunc uenit medicus cum quo ordinauerat truncare pedem suum $e t$ non inuenit illum . tunc dixerunt ili qui erant ibi . non est hic . sed hodie exiuit sumo mane operari . tunc miratus est $\left(37 \mathrm{v}^{0}\right)$ medicus . et iuit ad canpum ubi operabatur ille et ${ }^{3}$ cum uideret ipsum laborando et glorificauit deum. Hoc significat quod nulus homo debet credere ad suam cogitac[ion]em ${ }^{4}$. nisi quando est bona:

1 Zu tilgen.

$2 L$. succurrere.

3 Kaum erkennbar.

* Die Buchstaben ion sind nicht zu erkennen. 
I9.

Ein Hirsch umringt von einem Löwen, einem Schaf, einer Ziege und einem Ochsen. Ein Löwe, der einen Hirsch verzehrt (leo qui comedit ceruum). Ein kleiner Mann in braunem Gewand und grüner Kapuze wendet sich von einem grofsen, reicher gekleideten und bewaffneten $a b$.

$\mathrm{L}$ Eo $e t$ capra ouis $e t$ uaca uenerunt in magnam siluam . et aprehenderunt unum ceruum . et leo qui forcior erat omnibus . totam partem abstulit aliis. Istud dictum est ad castigacionem nostram . quia nunquam debemus sociare cum maioribus uel forcioribus nobis . quia si iungimus cum illis qui tolerint 1 anobis nostra. non respicientes ad deum neque ad homines.

20.

Zwei Männer, jeder mit einem Scepter oder einem am Ende mit Blältern besetzten Stabe in der Rechten. Daneben eine rundlich sich erhebende Fläche, auf der kleine Sträucher stehen; darüber eine Wolke und Sterne.

7 Erra illos homines significat . qui non abent curam de celestibus . sed tantum curam habent de terenis . et non castigant 2 se pro celestibus sed pro terrenis.

21.

$\left(38 r^{0}\right)$ Drei Engel mit Heiligenscheinen und Flügeln, zu beiden Seiten je drei Menschen mit betend erhobenen Händen (angelos).

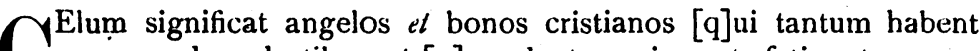
curam de celcstibus et [n]on de terrenis . set fatigant se pro celestibus:

22.

Mann mit einem Scepter in der Rechten, einem Apfel(?) in der Linken (iste uiuit in magnis deliciis); ein Mann wirft sich, den Kopf voran, in einen Zuber oder Brunnentrog (. hic moritur.).

M

Are significat mundum quia mare nunquam stat quietum sed senper est in turbacione : sic iste mundus numquam est quietus sed senper est in turbacione et periculo . et nunquam manet in uno statu . quia iste mundus sic est miser quia quando unus homo est in magno statu uel in gaudio et putat multum uiuere cito moritur et forte uadit ad infernum . et quando maior $u^{3}{ }^{3}$ est et peior plus habet tormenta. et nichil portat secum nisi peccata . sicut dicit scriptura . homo natus de muliere breui uiuens tenpore. et sic transit quasi flos canpi:

1 . cum illis tolent.

2 $L$. fatigant.

8 L. quanto maior. 
23.

Baum, auf dem ein Nest liegt; von ihm weg bückt sich ein Mann (pernicator) hinter einem an der Erde hüpfenden Vogel her. Baum mit Nest (etwas beschädigt); noch ein Baum mit Nest, auf diesem steht ein Vogel, drei kleinere Vögtl fliegen hinter einem gröfseren her vom Baume fort.

Über den zwei Bäumen steht pernices.

a) Ernices quando faciunt nidum cooperiut ${ }^{1}\left(38 v^{0}\right)$ illum ex omni parte . de finis ${ }^{2}$ ita quod alie uolucres [q] uas timent non $\mathrm{p}[\mathrm{os}]$ sint intrare ad eas. b) Et si [ali]quis homo approprinquat ei quando est in nido exit foras . et uoluntate sua monstrat ei qui appropinquat ad nidum.quod non possit uolare.et fingit se quod non possit currere pedibus . tunc homo qui uidet illa sic ire putat quod possit eam capere et uadit post illam. Tunc illa fugit et homo curit post eam . tantum quod sit longe anido . postea leuad se et fugit. c) Similiter abet aliam naturam . quia sic sunt luxuriose quod si uentus exit amasculo de solo odore fiunt pregnantes. d) Aliam nanque naturam abet . quod una furantur oua alterius . sed postquam nati sunt filii de illis ouibus . uadunt post illam de cuius fuerunt oua . et statim cum audierint uocem prioris agnoscunt eam et dimitunt illam que furauit oua . et hec est causa quare dicuntur pernices . quia perdit oua . sua ${ }^{3}$ et altera perdit pulos:

\section{4.}

Zwei Mönche (monachi .). Stadt (ciuitas). Haus, darin ein Mönch ein Weib umarmt (bordelum.). Wieder die zwei Mönche im Gespräch. Ein Mönch kniet vor einem auf einem Stuhle Sitzenden (hic accipit penitenciam).

$\mathrm{D}$ Vo monachi uenerunt ad ciuitatem ut uenderent que abebant laboratum . et quan $\left(39 \mathrm{r}^{0}\right)$ do fuerunt in ciuitatem . diuisit se unus ab altero . tunc unus ex illis cecidit in fornicacionem . postea uenit alius monachus el dixit ad eum. Eamus frater ad celam nostram. Et ille dixit non uenio. Ille autem respondit. quare frater. Et ille dixit. Quia quando separaui me ate . cecidi in fornicacion[em] Ile audiens talia contristatus est multum . et uolens liberare eum dixit . frater non dimittas propter hoc . quia ego eciam incidi in fornicacione. Modo eamus et simul abeamus penitenciam . el deus condonabit nobis peccatum. Qui quando fuerunt ad celam suam statim dixerunt ad suos maiores . quod fecerunt fornicacionem. Tunc sui maiores dederunt eis penitenciam quam uis non fecisset unus ex istis fornicacionem . tamen faciebat penitenciam . sicut et ille qui peccauerat . tamen non faciebat pro sc . sed faciebat pro fratre. Videns autem deus laborem et caritatem illorum . infra paucos dies reuelauit uni de maioribus suis quod pro multa caritate illius qui non peccauerat habebat dimissum illi qui fuerat fornicatus . et sic ille qui fecerat peccatum liberatus est apeccato . per caritatem illius qui non peccauerat. Vnde dico tibi ambula cum bonis . quia sicut conuersacio malorum homi-
- 1 L. cooperiunt.
2 L. spinis.
3 L. una. 
num $\left(39 \mathrm{v}^{0}\right)$ nocet . sic conuersacio bonor um proficit . sicut profeta testatur. Cum sancto sanctus eris et cum peruerso peruerteris: et salomon. Qui tetigerit picem inquinabitur ab ea. Et qui comunicat cum superbo . superbus fit:

$$
25 \text {. }
$$

Von einer Schlange (aspis) ist nur noch der Schwanz übrig; wo der Leib sein mürste, überklebtes Loch. Daneben eine Schlange, zu der sich ein Mann mit vorgestreckten Händen neigt (iste incantat). Ein Kopf und ein Arm ragen aus einer Wolke herab gegen einen Mann, der nach einem Tisch weist, darauf ein Becher.

a) Spis est quidem serpens qui si aliquando percutit hominem A moritur dormiendo. b).Et abet aliam naturam quam iam dicam. Incantatores solent uenire ad speluncam ubi est aspis ut in cantent eum. Tunc aspis quando scentit incantatorem qui uult incantare eum ut exeat de spelunca sua - ponit capud suum in terra . unam auriculam premit in terra . et aliam auriculam claudit cum cauda sua . et sic non audit incantatorem: Aspis significat hominem istius mundi qui claudit unam auriculam terrenis desideriis . et aliam auriculam claudit ut non audiat uerba celestia . in multis peccatis iacendo. Et ideo quando aliquis dicit ad alios uerba dei . et nolunt audire id . non tantum claudunt aures. sed eciam occullos suos excecant propter terrenas cupiditates . et sic nec uidere nec audire uolunt mandata dei . nec uolunt oculos ad celum leuare:

26.

$40 \mathrm{r}^{\circ}$ ) Ein Strauls (strucius.) emporblickend zu einem Sterne (stela). Ein Straufs, der. mit dem Schnabel im Sande wühlt. Ein Straufs, der zu einer Wolke aufschaut; unter dieser im Sande steckend drei Küchlein.

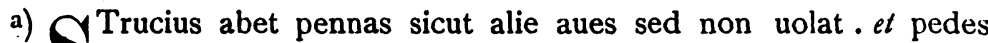
$\$$ abet similes gamello. b) Strucius quando uenit tenpus pariendi oua su[a l]euat occulos suos ad celum . et uidet quadam' ${ }^{\prime}$ stellam que uocatur uirgilia . que tunc incipit aparere. et non ponit oua sua interra nisi uideat stellam illam . que aparet quando messes florentur. Tunc st[ru]cius quando uidet stellam illam fodit terram ubi ponit oua sua et cooperuit oua sua de sablone in heremo. sed postquam recesserit aliquantulum aloco statim obliuiscitur et non recordatur de ouibus et amplius non redit ad oua.sed uirtute dei calor arene coquid ipsa oua et excludit. Quando strucius leuat oculos suos ad celum quando tenpus uenit pariendi oua. Significat quod nos debemus leuare oculos ad celum et cognoscere tenpus nostrum . leuare occulos cordis nostri ad deum . et obliuiscere terrena . et amare et sequi celestia:

1 L. quandam. 
27.

Zwei Vögel (turtura .) im Profil nach rechts gewandt. Ein ebensolcher; ein durchaus nackter Mann von vorn, den rechten Arm ausgestreckt, die linke Hand, die einen Stab an untern Ende hält, an die Brust gedrückt.

$\eta \nabla^{V r t u r}$ est auis que multum diligit maritum $\left(40 v^{0}\right)$ caste uiuit cum marito suo seruat sibi fidem . et si femina aliquo modo perdiderit masculum . aut masculus feminam . non contingit 1 se amplius cum aliquo . sed senper caste uiuit usque infinem. Quod turtur sic seruat suam castitatem. significat animam que postquam uidet maritum suum mortuum . id est socrum ${ }^{2}$ suum . nunquam contingit 1 se cum alio marito . sed desiderat uiuere senper in amore dei et in castitate.

\section{8.}

Schiff mit Ruderern und Segeln (nauis): Ein Bischof auf der Kanzel; vor ihm sitzende Zuhörer (episcopus qui predicat). Ein Bischof im Gespräch mit einem Weibe; etwas ferner noch zwei oder drei Weiber.

MRia sunt sine quibus nauis non potest procedere . silicet nauigator - gubernator . qui gubernet per rectam uiam. Nauis significat santam eclesiam. Gubernator significat cristum . uel patriarcham. Quia sicut nauis non potest ire per uiam rectam nisi gubernator gubernet eam. Ita cristiani qui uocati sunt eclesiam cristi.non possunt ire per uiam rectam . nisi per episcopum uel patriarcham uel aliquis bonus pastor aquo gubernentur. Et episcopus debet nunciare populo . praua relinquere . et senper bona facere . ne populus sibi comissus . cadat in $\left(4 \mathrm{I}^{0}\right)$ aliquod peccatum . et si unus homo uidet alium aliquod peccatum facere. [s]tatim debet ire ad suum pastorem . ut suus pastor conuertet illum auia sua mala et uadat per bonam uiam. Et hoc debet facere per uirtutem dulcis uerbis . eum amonendo et predicando. Quia sicut nautes nauigant ut uideant ire bene nauem . debent senper cristi populum adiuuare . ut ad deum possit accedere et in bonis operibus perseuerare. Quia nisi populus abeat episcopus ${ }^{3}$ aut aliquem doctorem sante cclesie non potest uiam rectam tenere:

\section{9.}

Zwei Berge (montes). Grofse mit Schild, Schwert, Helm bewehrte Männer (homines superbos). Kleine Männer in gebückter Haltung mit vorgestreckten Händen (homines humiles). Christus, die Rechte wie zum Lehren ausgestreckt, in der Linken ein Schriftstück (.xps.). Drei Männer ihm betend(?) zugewandt.

Ontes significant superbos homines. Valis [au]tem significat hum[i]les et sinples homines sicut in euangelio legitur. Omnis ualis exautabitur. et omnis mons et collis humiliabitur . hoc

1 . coniungit.

2 Man kann auch socium lesen.

3 L. episcopos oder episcopum. 
est deponere superbos asuperbia sua. Et fuit dictum hoc propter iudeos qui cum essent superbi propter legem quam habebant postquam cristus uenit in mundum . depositi sunt asua superbia . set uales sunt implete . hoc fuit pagani qui non erant superbi propter aliquam legem . sed erant humiles et superbi ${ }^{1}$. $\left(4 \mathrm{I} \mathrm{v}^{0}\right)$ et propter $\mathrm{h}[\mathrm{oc}$ fu]erunt impleti diuinis preceptis ideoque dic[it s]criptura. Omnis ualis implebitur et cetera: De quibus et in alio loco legitur. Descendunt montes in conualibus. hoc est precepta dei . que toluntur de cordibus superborum hominum . et inplentur corda humilium . sicut in alio loco legitur. ubi ipse domin $u$ s dicit. Super quem requiescet spiritus meus nisi super humilem et quietum et timentem uerba mea - quia spiritus dei nunquam poterit habitare in cordibus superborum sed incordibus humilium habitat. Quia sicut superbia est radix omnium malorum . sic humilitas est radix et fundamentum omnium bonorum uirtutum. Et propter hoc dicit salomon. Odibilis est coram deo et hominibus superbia:

\section{0.}

Vier Männer neben einander; der erste scheint zum zweiten, der dritte zum vierten zu sprechen; der zweite und der vierte sind bewaffnet.

Tlus homo debet habere in hodio fratrem . sed malum quod facit debet habere in hodio. sicut dicit santus augustinus. homines sic sunt amandi.ut eorum non diligantur errores.

\section{$3 \mathbf{I}$.}

Christus (. cristus.) zieht Eva aus der Seite des schlafenden Adam (adam et eua). Adam und Eva, jedes einen Apfel zum Munde führend unter einem Baum, um den sich die Schlange (mit Menschenkopf) windet. Adam und Eva von einem Engel, der ein Schwert führt, aus dem Paradies gestofsen. Christus, nach dem sich eine Hand aus einer Wolke ausstreckt.

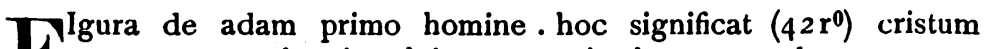
contra quos homines ${ }^{2}$ ipse creauit . hoc est adam et euam insurrexerunt . et contra illum peccauerunt . postea deus dedit eos inmortem quando expulit eos de paradiso . sed postea deus moderator ${ }^{3}$ mandauit filium suum in Mundum . qui per passionem șuam et per suum sanguinem liberauit omnes homines tocius mundi amorte anime:

\section{2.}

Nackte Menschen von den Knieen an aufwärts sichtbar stehen wit erhobenen Händen in einem offenen Grabdenkmal (homines qui resurgunt.). Männer sitzen auf einer Bank; über ihnen schweben unbekleidete Gestalten. Drei Männer bearbeiten die Erde mit Hacke und Rechen.

$\mathbf{Q}^{\mathrm{v}}$ Vando homines resurgent in die iudicij erunt in etate triginta annorum . et illi homines qui erunt boni tantam uirtutem abe-1 bunt in celum . quod statim quando illis placebunt 4 erunt in

$1 L$. et non superbi.

3 L. miserator.
$2 L$. contra quem homines quos.

L. placebit. 
terra et quando illis placebunt ${ }^{1}$ erunt in celo. Et nulus murus uel aliqua causa poterit contrastare illos quod ipsi non uadant per medium murum ita quod neque murus ipsos corrunpat. Sed mali homines nulam uirtutem habebunt . et erunt in maiori corrupcione quod fuissent in hoc mundo. $\mathrm{Et}$ boni intantam gloriam erunt . quod totum mundum simul uidebunt:

33 .

Bischof mit Stab und Mitra auf hoher Kanzel stehend; sitzende Zuhörer vor ihm (episcopus qui. predicat). Prediger auf einer Kanzel. Sitzende Zuhörer einem vor ihnen stehenden Bischof zugewandt.

$\mathbf{E}^{\mathrm{r}}$ Piscopus uel quilibet eclesiasticus doctor debet $\left(42 v^{0}\right)$ habere sapienciam el ducere bonam uitam . quia sapiencia sine bona uita facit hominem superbum . bona uita sine doctrina facit hominem inutilem. Predicacio sacerdotis debet confirmari per bona opera . ita quod instruantur ${ }^{2}$ exemplo quod ipse docet uerbum. Nula enim causa turpior est quam bene predicare et male uiuere: Vnde dicit beatus augustinus . bene autem loqui et male uiuere . nichil aliud est . quam se sua uoce dampnare: vnus quisque prediçator debet habere studium ut bene predicet et bene faciat . et unus ${ }^{3}$ sine altero esse non debet. Sed in primis debet bene facere ut postea bene et firmiter possit predicare. Ipsa uero-doctrina quam predicat aliis fit uile proficuum doctoris ${ }^{4}$. quia qui bene predicat et non tenet . facit doctrinam suam in utilem: Qui bene docet $e t$ male uiuit est quasi cinbalum quod apud alios sonat $e t$ se ipsum non audit. Qui bene docet $e t$ male 5 uiuit facit proficuum audientibus . set qui male uiuit se ipsum occidit. Qui bene docet et male uiuit est quasi cereus qui dum aliis lucem dat. se ipsum confundit et consumat: Odibilis est coram deo et hominibus superbia. ideo quia radix est omnium malorum . omni ${ }^{6}$ homo qui peccat superbus est coram dei precepta. et sicut superbia $\left(43^{0}\right)$ est omnibus ' peccatis sic homo nunquam peccare potest nisi per inobedienciam mandatorum dei. Omnis superbia tanto magis profunde cadit quanto plus se leuat. et qui se eleuat per superbiam . fit humilis per dei iusticiam . superbia non tantum est in illis qui male faciunt. sed eciam in illis qui bene faciunt. Certe omne bonum quod facit homo sine humilitate $c t$ caritate . deputatur ei ingrande peccatum $e t$ in uicium. Diabolus per superbiam de celo fuit eiectus. Ille uero homo qui de uirtute sua 8 eleuat similis est diabolo.quia de excelso cadit propter hoc ut grauiter ruat.et propter hoc maius peccatum est superbia quam omnia mala uicia et quia qui confidunt mente humana subiacet ${ }^{9}$ uiciis.

$1 L$. placebit.

$2 L$. illustretur $P \quad 3 L$. unum.

- $L$. facit vile proficuum doctori.

S $L$. bene.

$6 L$. omnis.

8 L. sua se.

$7 L$. in omnibus.

9. $L$. subiacent. 
34.

Mann, der die Linke auf ein auf einem Tisch liegendes Buch, die Rechte auf die Brust legt (iste iurat); ihm gegenüber ein Mann mit erhobenem Zeigefinger der Rechten, auf einer Bank sitzend (et iste est iudex). Zwei Männer neben einander und vor ihnen ein dritter einem vierten gegenüber, der wieder auf einer

Bank sitzt.

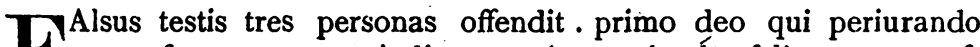
se refutat . postea iudicu que 1 menciend́o falit. postea offendit innocentem quem ipse dedit 2 falso testimonio. Quando simul sunt falsi testes tarde potest cognosci falsitas mendacii . quod si separati fuerint . falacia eorum cito manifestatur.

35.

(43 $\left.v^{\circ}\right)$ Drei Männer sitzend, einer ein Buch an die Brust gedrückt; über ihren Häuptern rote Flammen (iudices qui iudicant falsitatem); vor ihnen drei Männer, die Hände zeigend nach ihnen ausgestreckt; nach diesen weist eine Hand aus einer Wolke.

$I^{\prime}$

Vdices et omnes potestates qui minoribus suis conturbaciones faciunt in eterno incendio ardebunt . testante domino per esaiam profetam: Iratus sum super populum meum et propter hanc causam descende et sede in puluerem et tace et intra in tenebras - lieniet super te malum calamitas et miseria qe nunquam ate poteris refutare.- Et dedi illum in manu tua et non habuisti de ilo misericordiam - sed nimis grauiter habuisti potestatem super populum meum. Adeo pasșurus es supradicta:

\section{6.}

Schwarzer Vogel auf einem Baum, den Kopf abwendend von einem Nest mit drei weifsen Vögeln. Schwarzer Vogel auf einem Baum einen von drei schwarzen Vögeln in einem Neste fütternd (coruus qui pasit filios suos.).

Christus eine Schrift in der Linken, mit der Rechten einen Knieenden segnend ( $x \bar{p} s$ qui dat benedicionem).

0

Oruus hanc naturam habet . quia quando facit filios sunt albi . et non dat eis manducare donec nigri fiant. Hoc significat quod nulus homo debet se desperare de misericordia dei . quia sicut deus pascit illos coruos sic et plus passit nos.si nos habemus spem in eo:

37.

Drei Bewaffnete (homines superbos.); zwei Männer mit Hacke und Rechen (homines humiles.). Ein (blauer) voller Mond und eine Mondsichel. Eine Kirche (eclesia.).

$\left(44^{r}\right)$ Tna significat stultos homines istius mundi . qui ${ }^{3}$ sicut luna cressit et decressit et nunquam permanet in eodem statu . sic stulti homines crescunt et decrescunt propter illorum superbiam . et nunquam in eodem $s[$ tatu] permanent. Crescunt in
1 L. iudiciquem.
2 L. ledit ?
${ }^{3}$ L. quia. 
prosperitatibus suis - postea per superbiam leuantur . decrescunt $\mathrm{qu}[\mathrm{ando}]$ in aduersitate franguntur. Solent homines huius mundi amatores esse multum superbie . et eleuare ${ }^{1}$ in prosperitate. et in aduersitate multum se frangit ${ }^{2}$. et quod peius est aliquando desperare se . quod est grande peccatum - unde dicit scriptura. $\mathrm{Ne}$ prospera te eleuent. nec te aduersa conturbent. Quando aliquis homo est in aduersitate . non debet se desperare de misericordia dei . quoniam deus non spernit sperantes in se: Similiter quando homo est in prosperitate non debet superbire. set senper debet timere ne propter peccata sua contingat 3 illi aduersa: $\mathbf{E r}$ aliam significacionem habet lunam et sol $^{4}$ significat sanctam eclesiam . que sicut luna deficit aliquando . sic humilitas cristi et mortua est et post tres dies resurrexit amortu $\times$ is.

\section{8.}

Sonne (. sol .), Christus in der Geberde des Lehrenden (. x̄̄s .), Mond (. luna .) $\mathrm{Q}^{\mathrm{Ol}}$ significat diuinitatem cristi . quia sicut $\left(44^{\circ}\right)$ sol est dignior quam luna et multum plus lucet, sic diuinitas cristi magis est [d]igna et magis lucet . quam aliquid aliud.

\section{9.}

Mann mit einer Lanze hinter einem Baum kauernd (latro qui stabat absconsus.), dem sich cin Löwe nähert (. leo .). Haus oder Turm, aus dessen Fenster drei Köpfe sichtbar werden (unam prisonem.). Drei mit Schwertern bewaffnete Männer; auf Knieen und Händen liegt vor ihnen ein Mann (isti occidunt latronem .). Drei Männer getrieben, gestofsen, gestachelt(?) von einem vierten (einem Teufel?).

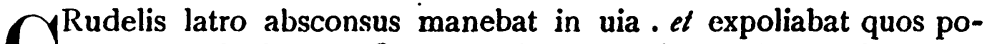
terat aprehedere. ${ }^{5}$ Quadam uice uenit leo et inuenit latronem iacentem . et statim aprehendit illum et dixit ad eum. Si uis uiuere dic michi ueritatem cito . quare iaces hic absconsus: Respondit latro dixit ${ }^{6}$ ad leonem. Non audeo tibi dicere nisi ueritatem. Culpatus sum ameo seniore et senper expectaui ut reduceret me in suam bonam uoluntatem. Dixit leo. Credo quia mentiris michi . tamen si dicis uerum dic michi quot dies mansisti. Ft latro habitauerat ibi per tres annos . sed falax dixit illic mansisse per decem dies. Respondit leo. Modo te cognosco mentiri - quoniam uestimenta tua sordidata sunt . et monstrant quod per multa tenpora hic mansisti: Dixit latro . talem te uideo . quia tibi non audeo mentiri . propter bestias quas occidi . sunt uestimenta mea sordidata. $\left(45 \mathrm{r}^{0}\right)$ Respondit leo. Tu dicis quod times me. et non cessas mentiri . tu male facis: Nunquid ${ }^{7}$ plus uolo uiuere

1 L. eleuari oder se eleuare.

$2 L$. frangi oder se frangere.

3 L. contingant.

Zu tilgen.

- $L$. aprehendere.

- $L$. et dixit.

7 L. nunquam. 
dixit latro si tibi sum mentitus. Audientes hoc illi qui clausi erant in carcere alatrone . subito clamauerunt uoce magna et dixerunt: Domine leo nolite credere sibi . quia iste crudelis latro est et homicida. Tunc leo audiebat illos sed non uidebat.qui dixit ad latronem. Qui sunt illi quorum uoces audio? Respondit latro et dixit nescio: Dixit leo. Modo apparet quod mentitus es. Respondit latro. Non sum . quia sio os qui mentitur occidit animam . et propter hoc nec tibi nec alicui uolo mentiri unquam. Tunc miseri qui erant ligati senper clamabant auta uoce dicentes. Odomine leo succurre nobis . et libera nos de isto carcere et ne dimitas latronem efugere de tua potestate. Tunc leo multum iratus et cum grande ira dixit ad latronem. Quare non timuisti me et mentitus es michi . deberes michi semel dixisse ueritatem. Respondit latro. Audi domine leo.si ueritatem non dixi tibi . anima mea senciat pennam ininfernum. Dixit leo. Credo quod corpus senciat pennam. Et iussit illos miseros qui erant ligati exire de carcere . et dixerunt ad leonem omnia que latro fecerat. Tunc: leo precepit illis ut occiderent eum.$\left(45 \mathrm{v}^{0}\right)$ et illi sic fecerunt. Hec tabula significat quod illi qui faciunt malum aliis . multociens cadunt in magnum periculum et iam aliquando sunt mortui.

40.

Zwei kleine Frösche; ein grofser Frosch (rana.). Ein grofser Frosch seitwärts fallend. Ein Ochs (. bos.). Ein Weib und ein Mann, letzterer sinkt um.

Ana cum uideret bouem grassum iacentem desiderans fieri 1 magna sicut bos . inflauit se et dixit ad filios suos. Videte filii sum ego tam grandis sicut bos.et ili dixerunt non . postea inflauit se multum ut possit fieri grandis sicut bos . et cum inflaret se fracta est pellis eius et mortua est. Hec fabula significat quod nulus homo debet se facere maiorem quam sit . quia qui facit se maiorem quam non sit . perdit se ipsum:

\section{1 .}

Eine springende Katze (.gata.). Eine Katze an einer Kette emporkletternd fafst oben eine Maus. Katze mit einer Maus im Maule. Ein Mann schlägt (oder drückt?) mit einer Stange einen andern auf den Kopf.

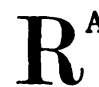
Atus cum uellet descendere per catenam ut raperet carnes . gatus cucurrit ad illum et statim aprehendit eum et dixit. $\mathrm{O}$ miser si ego non occurrissem tibi . tu cecidisses in foco. Respondit ratus. Si modo non occideres me. sed dimitteres. ego crederem quod tu ueles me adiuuare et si pro tua bonitate succurristi me . modo dimit $\left(46 \mathrm{r}^{0}\right)$ te me reuertere in domum meam. Et dixit gat $u s$. Quod proficuum haberem ate de hoc facto site dimitterem $e t$ unus de parentibus meis conprehenderet te.modo adiuui te. sed si parentes mei caperent te . non possem te postea adiuuare. Respondit ratus. Melius esset michi medium arsum de foco exisse . quam omni hora de morte mea timere. Tunc dixit gatus. Ego liberaui te de foco.modo liberabo te de omni cogitacione. et 
statim occidit illum et comedit. Hec fabula significat illum hominem . quia 1 quando uidet alium in periculo non dolet sed magis confundit illum:

42.

Frosch im Grünen (rana), Ratte kommt hinzu (. ratus.). Frosch und Ratte auf dem Hintern sitzend. Ratte auf dem Rücken des Frosches. Grofser Mann mit ausgestreckten Händen; vor ihm am Boden ein kleiner; ein dritter daneben, auf den eine Hand aus den Wolken weist.

Atus cum uidisset ranam manducatem ${ }^{2}$ herbam dixit ad illam. R. O quam malum cibum manducas. Respondit rana. Et tu quale cibum manducas? Respondit ratus omnia bona. Et dixit rana . ego ueni per dileccionem ad hunc locum . quia habeo domum meam plenam de multis bonis . tamen precor te ut uenias mecum in domo mea et bibamus in caritate. Respondit ratus. Non modo. sed si placet tibi ueni prius mecum ad domum meam et bibamus simul. Tunc rana iuit cum rato ad domum $\left(46 \mathrm{v}^{0}\right)$ rati et ratus dedit ei manducare cortices de castaneis et de nuce et ossa sica. Respondit rana et dixit quod non poterat manducare de hoc cibo . et dixit. non est mirum si tu es grassus . atque formosus . quia comedis tam bonis cibis . de quibus pro tua caritate multum sum bene repleta . sed posquam tu amas me et duxisti me in domum tuam . senper tecum uolo gaudere in caritate . et senper uolo uenire ad domum tuam et tu ad meam . et modo deprecor te multum ut tu modo uenias mecum ad domum meam . et manducemus et bibamus simul. Tunc iuit ratus cum rana . set cum ipsi uenissent iusta aquam . dixit ratus . ubi est domus tua. Respondit rana . ultra aquam . sed sta modo et ascende superme . et monstrabo tibi ire super aquam . quia tu nescis ire ad huc . et ego portabo te saluum et reducam. Tunc ratus ascendit super ranam ut transiret ultra aquam. Rana cum fuisset intus in aqua submersit se . et ratus cepit bibere non per suam uoluntatem et cepit multum timere et dixit ad ranam - precor te multum ut modo repatriemus ad domum meam . crastina die ueniam tecum ad domum tuam. Respondit rana. Ego proter bonitatem tuam modo satis sum repleta de multis bonis cibis, quod dedisti michi . modo bibamus suficienter si placet tibi et postea re $\left(47 \mathrm{r}^{0}\right)$ uertamur . et postquan rana dixit hoc. dimisit illum in aqua. Hec fabula significat quod ille homo qui male facit proximo suo.male recipiet adomino.quia raro solet uenire quod homo reeclat meritum bonum pro malo.

\section{3.}

Fuchs (. uulpis.) und Hirsch (ceruus). Der Hirsch nimmt des Fuchses Kopf zwischen die Hörner. Zwei Männer im Gespräch.

T Vlpis cum uideret ceruum dixit ad illum. O cerue . quantum cornua tua ornant te . tantum cauda tua deturpat te. $\mathrm{Si}$ cupis me predicare ${ }^{3}$ et uis michi dare partem de tuis cor-

1 L. qui.

2 L. manducantem.

3 L. praeditare. 
nibus. de mea cauda laudata possum iuniere in tua cauda deturpata. Ceruus pacienter respondit ad uulpem . tua cauda non est michi amata . talem uolo abere qualem deus uoluit michi dare . sed tamen uolo tibi dare partem de meis cormibus . et uolo tibi dare integrum cornum . sed statim leuauit uulpem in cornibus suis et iactáuit eam plagatam in terra . et dixit . de tuo maiore et forciore. noli plus facere derisionem: Ista fabula significat quod nulus homo debet facere derisionem de suo maiori neque de suo forciori:

\section{4 .}

$\left(47 v^{0}\right)$ Pferd am Boden liegend (cabalus macer); ein anderes springt davon (cabalus grasus). Wiederum ein Pferd an der Erde liegend, ein zweites mit umwickelten Beinen kommt $\mathrm{zu}$ ihm. Ein Pferd geht nach rechts ab. Ein grofser Mann führt einen kleineren an der Hand.

Abalus grassus cum cureret huc et illuc . uidit alium cabalum magrum multum el cepit percutere eum el calcitrare . el uidit 1 illum habentem dorsum et spatulas plagatas et plenas de uermibus dixit ad illum. Vate et tole te aconspetu meo oputrede. et noli plus stare ante me . quia non possum sustinere te propter magnum despectum tui corporis. Respondit macer cabalus cum grande paciencia . et dixit ad cabalum grassum. $\mathrm{O}$ domine . quare habes me in despectum . iam fui ego pulcer et grassus . et sicut tu es eram ego . et nichil peius de te quando eram cum domino meo. tu male facis quod non doles de me. et non abes misericordiam mei set exaltas te. Et cabalus grassus calcitrabat cabalum magrum et dicebat cum magna superbia et ira. Oputrede quomodo es ausus stare ante conspectum meum ${ }^{2}$ et loqui contra me quia ${ }^{3}$ sic sum formosus et pulcer . et postquam dixit hoc calcitrauit et iactauit eum longe ase. Postea non post multos dies cum staret in stabulo cum magna dignitate pessimus morbus uenit in pedibus suis et prostrauit se in terra $\left(48 \mathrm{r}^{\circ}\right)$ et non poterat sursum surgere. postea leuauit se et iuit ad campum ubi stabat alius cabalus macer. Et cum ille uidisset eum qui erat macer et miser appropinquauit ad illum et dixit. Tu es macer modo et abes pedes inflatos noli perturbari . sed sta hic quantum potes nocte ac die . quia talis herba est hic ${ }^{4}$. que sanabit pedes tuos. et postea recordabit te de mea infirmitate et cabalus qui erat antea macer repatriauit in stabulo cum honore . et superbus remansit solus in canpo cum pudore. Hec fabula narrat quod nulus-homo debet abere in despectum suum minorem. Sicut dicit in cuangelio. omnis qui se exaltat humiliabitur . et qui se humiliat exaltabitur.

$1 L$. videns.

2 In der Hs. stand erst meo; dem o wurde ein $\overline{\mathrm{u}}$ übergeschrieben.

3 L. qui.

- Das h von späterer Hand zugesetzt. 
a.

Von hier ab stehen die Bilder am äufseren Rande, sind aber teilweise verloren, da ein Stück des Randes herausgerissen ist.

Mann, der zwischen den beiden Hälften eines Thürvorhanges hervortritt; verletzt (. ianuarius.).

MEnse ianuarii sanguinem noli minuere . lectoarium accipias in mane . postea uinum bibe çinçiber comede capud ne laues:

Bild verstümmelt.

MF.nse februarii sanguinem minue. mel confectum ama ad purgandas fleomas appium eo tempore bonum est:

Bild verstümmelt; ein Mann, der in ein grofses gekrümmtes Horn störst.

MEnse marcij dulce manduca dulce bibe . porros cotos comede . balncum sanum est sanguinem noli minuere pocionem non accipias . quia ipsa solucionem frigus genenerat 1 . polegium bibe ad stomachum calefaciendum . el rutam ad occulos purgandos.

$\left(48 v^{0}\right)$ Reiter auf galoppierendem Rosse (aprilis).

MEnse aprilis sanguine 2 minue . carnem recentem manduca . pocionem accipe . dolorem stomaci purgat . unguento calisti coutitur ${ }^{3}$. nulla radice comedere . pipinelam et bertonicam bibe:

Langhaariger Mann, in beiden emporgehaltenen Händen Blumen (madius).

MFnse madii sepe laua tibi capud . cibum caldum noli comedere . uenam epaticam incide . agrimoniam dilige. nec capud nec pedes non manducare . asencio et fenuculo sepe bibe.optimum est ad colera minuendo:4

Mann, der mit der Sense (?) arbeitet (junius).

MEnse iunii ieiunus omni die bibe uinum album sine aqua. latucas manduca - acetum ama quia tunc humores de rebus procedunt:

Mann mit geschwungenem Dreschflegel(?) (iulius).

MEnse iulii ab uenere abstine saguinem noli minuere pocionem non accipias. saluiam et rutam et gamandream frequenter uisita 5 - aquam frigidam ieiunus bibe:

Bild fehlt. MEnse augusti . agrumen manduca - caulos et bletas non comedere . quia colera nigra faciunt. febres mutant pro ructacionem . saluiam bibe . sagimen frictum non comedere.

MEnse septenbris omnia quod uis accipe quia co tenpore confecta sunt omnia . ieiunus bertonica bibe:

MEnse octubris recentum 6 manduca . mustum bibe. corpus sanat et solucionem facit . lac caprinum ieiunus bibe.ad sanguinem dul $\left(49 \mathrm{r}^{(1)}\right)$ ciandum et pulmonem emendandum:

1 L. generat.

3 L. co-utitor ?

5 L. usita.
2 L. sanguinem.

4 L. choleram minuendam.

6 L. racemum ?

Zeitschr. f. rom. Phil. XII. 
Mann mit Hut wärmt die Hände überm Feuer? (nouember).

MEnse nouenbris uenam epaticam incide . balneum ne ames . quia sanguis coagulatus est . nec ${ }^{1}$ calore balnei humores moueantur.

Mann, der sich auf einem Fuchs (?) geworfen hat und ihn erdrosselt; darüber steht decenber, darunter iste occidit uulpem.

MEnse decenbris . caulos noli comedere . saturegiam bibe . que bona est pro ructacione et sana est in eo tenpore. Et si ita feceris pro uno quoque mense sicut dictum est . in illo anno infirmitatem non abebis.

b.

TOlle sanguinem uulpis recentem . et super pectinem pone . et unge - presentes lapides que sunt in uesica frangit:

Mann, der die rechte Hand mit ausgestrecktem Zeigefinger dem Ohre nähert (s. die vorige-Beischrift, die vielleicht hierher gehört, in welchem Falle der Maler arg milsverstanden hätte).

$\mathrm{AD}$ eum qui dormire non potest . cera de auricula onagri fronti inlinito statim dormit:

Sitzender; daneben ein Weihwasserbecken mit Wedel?

ACcipe aquam santam in alico uaso . et ramum de oliuo . et munda ipsum et fac tres truncos. et quando incidis dicas tres pater noster - et ubi dicitur libera nos amalo. dicat libera hunc famulum tuum aterciana . et pone unum truncum in aqua sancta predicta. Postea incide alium cum tribus pater noster. et postea alium et pone in aqua . et da illam aquam ad infirmum cum tribus pater noster. quando febrem capit illum:

c.

$\left(49 v^{0}\right) \Delta D$ explanandum sompnium

In .A. significat adiutorium domini.

In .B. significat aliquod bonum.

In .C. significat sanguinem.

In .D. significat inimicum.

In .E. significat noua uidere uel audire.

In .F. significat malum prope esse.

In .G. significat gaudium.

In .H. significat ad esse gaudium.

In .I. significat alibi ire.

In .K. significat in eodem loco stare.

In. .L. significat leticiam ad esse.

In .M. significat aliquod magnum.

In .N. significat aliquod contrarium.

In .O. significat elemosinam facere.

In .P. significat pietatem exercere.

1 L. ne. 
In .Q. significat ad deum curere.

In .R. significat fossa mortis.

In .S. significat salutem domini.

In .T. significat tristiciam ad esse.

In .V. significat uenire adorare.

In .X. significat saluatorem ad esse.

In.$Y$. significat id adiuuare.

In .Ç. significat mortem adesse.

Schlafender (iste dormit.). Sitzender mit Buch anf den Knieen (iste splanat somnia.), ihm gegenüber drei Sitzende, von denen einer etwas vorzutragen scheint.

Anmerkungen.

I. Die eigentlichen Physiologi (wie die von Göttweih und von Bern) gedenken der Spinne nicht; dagegen findet sich eine Nutzanwendung von dem Mückenfang der Spinne und von der Zerstörung ihres Netzes durch den Wind auch bei Petrus von Mora s. Pitra, Spicil. solesm. III 8I, womit noch S. 430 Anm. zil 6o zusammenzuhalten ist. Weiter gehört hierher das Exemplum des Odo von Ceritona (über Heimat und Zeit des Odo s. P. Meyer in Romania XIV 388), das man bei Hervieux, les Fabulistes latins II 607 und in der gekürzten Fassung eb. S. 76I findet. Der prosaische Bestiaire des Pierre deutet den Mückenfang der Spinne auf die List des Teufels und schweigt vom Winde, s. Cahier und Martin, Mélanges d'archéol. II 21 2, Paris 1851 .

2. S. den Göttweiher Physiologus (Archiv f. Kunde österreich. Geschichtsquellen V, Wien 1 850) Nr. XIX und die von Brüssel und von Bern bei Cahier und Martin, Mélanges d'archéologie II I65, den griechischen bei Pitra 344 .

3a. Die Erneuerung der Schlange griechisch bei Pitra $347 \mathrm{~b}$ 25, lateinisch (Ansileubus) eb. 419 b I 2, Göttw. XI (Viper) S. 566, Bern und Brüssel. Cah. u. M. II 218 . - 3 b. Ausstofsung des Giftes vor dem Trinken Pitra 348 a 14, 419 b 20, Göttw. XI S. 566; fehlt in den Texten von Bern und von Brüssel oder ist bei Cah. und M. wenigstens nicht mitgeteilt. - 3c. Flucht vor dem Nackten, Angriff auf den Bekleideten Pitra 348 a 22, 419 b 24, Göttw. XI S. 566, Brüss. bei Cah. u. M. II 144. - 3 d. Preisgebung des Leibes (Fürsorge für den Kopf übergeht unser Text) Pitra 348 b I I, 4 I9 b 28, fehlt Göttw. und bei Cah. u. M. und ist auch in unserem Texte bei der Deutung übergangen.

4a. Die Fürsorge für den Winter veranlafst in den Physiologen die Ameise nicht allein zu sammeln, sondern die Körner entzwei zu beilsen, damit sie nicht im Winter keimen, Pitra 349 a 16 , 419 a 30, Göttw. XVII S. 572, Cah. u. M. II 190. - 4b. Das Verschmähen der Gerste findet sich mit Deutung daselbst ebenfalls; 
die nicht eben geschickte Anwendung unseres Textes scheint ihm eigentümlich.

5 a. Pitra 359 a 10, Göttw. XIII S. 568 und stark abweichend bei Cah. u. M. III 268. - 5 b. Von der Art, wie die Hirsche über das Wasser setzen, berichten die Bestiarien nicht, wohl aber Plinius VIII I 14, Aelian V 56; vgl. Brunetto Lat. Tres. 234. - Alter allerius onera portate et sic adimplebitis legem Christi, Galat. VI 2.

6. Pitra 350 a 5, Göttw. V S. 559, Bern. u. Brüssel. Cah. u. M. II 173, wo übrigens der untere Teil des Sirenenleibes Vogelgestalt hat (nur in einem für die Varianten benutzten Texte ist wie in einigen französischen von Fischgestalt die Rede). In sehr loser Gedankenverknüpfung kommt unser Text von den sittenlosen Predigern auf die guten und von den Wundern (Blindenheilungen) dieser auf die Blindheit der Sünder und den Sündenfall. Populus gentium u. s. w. Matth. IV 16.

7a. Das Ziehen in Schaaren meldet Plin. VIII I I (vgl. Brun. Lat. 243), 7b. die Art der Begattung ders. X 173 (Brun. Lat. 244); $7 c$. von dem einzigen Jungen trotz dem langen Leben berichtet ders. VIII 28 (Brun. Lat. 244); 7d. dals der Elefant nur wenig Krankheit kenne, ders. VIII 28. Das übrige stammt aus dem Physiologus: 7e. das Junge wird im Wasser geworfen (der Grund dafür ist aber abweichend angegeben) Pitra 365 a 8 (Ansileubus eb. 4 I 8 b I6), Göttw. VIII S. 562, Cah. u. M. IV 57; 7f. das Anlehnen zum Schlafe an einen Baum Pitra 365 a 20, Cah. u. M. IV 58; $7 \mathrm{~g}$. die vergeblichen Bemühungen der grofsen, die erfolgreichen der kleinen Pitra 365 b 3, Cah. u. M. IV 58; 7h. Wirksamkeit der verbrannten Haare Pitra 365 b I 3 (Ansil. 418 b 27), Göttw. VIII 563, Cah. u. M. IV 58. Im Physiologus findet sich auch die Deutung von 7g. auf Moses, die Propheten und den Erlöser.

8. Pitra 35 I a 24 , Göttw. II S. 553 , Cah. u. M. III 238, wo der im griech. Texte fehlende Zug hinzukommt, dafs der Drache allein dem Geschrei und Geruch nicht folgt). Vgl. Odo von Ceritona bei Hervieux II 637, Brun. Lat. 249.

10. Die zwanzigste Fabel des Avianus, über deren Bearbeitungen Robert oder Regnier zu Lafontaines Fabeln V 3 Auskunft geben.

I I. Die achtzehnte Fabel des Avianus, über deren anderweitige Behandlung man Regnier zu Lafontaine IV I 8 vergleichen mag.

I 2. Die sechzehnte Fabel des Avianus; s. zu Lafontaine I 22; Romulus Österleys zu App. 18.

13. Die sechsundzwanzigste Fabel des Avianus; s. Österley zu Kirchhofs Wendunmuth VII 18.

I4. Die zweiunddreifsigste Fabel des Avianus; s. zu Lafontaine VI I 8.

15. Die vierunddreilsigste Fabel des Avianus; s. zu Lafon- 
taine I I. Romulus Österleys 4,19; bei Hervieux auch 473, 558, $724,772,802$.

16. Legende vom Einsiedel, der sich die Finger verbrennt; s. Wrights Latin stories XVII S. I 8 De muliere quae voluit decipere heremitam und Hervieux II 666 (aus dem „ersten Fortsetzer" des Odo von Ceritona); frz. in den Vies des anciens pères No. 25 nach dem Verze'chnis in Romania XIII 240, ital. bei Cavalca P. III C. I 39 (Ausg. von Triest 1858 S. 210).

17. Legende vom Einsiedel, der um der Tochter des Götzenpriesters willen den Glauben abschwört; franz. in den Vies d. anc. pères No. 3, ital. bei Cavalca P. III C. 140 (S. 211 ).

1 8. Legende von dem, der aufgehört hatte all seinen Erwerb an die Armen zu verteilen; bei Hervieux II 669 (1. Forts. des Odo); franz. in Vie d. anc. pères No. $5 \mathrm{I}$; ital. in Ulrichs Recueil d'exemples italiens No. r, Romania XIII 28.

19. Die fünfte Fabel von des Phaedrus erstem Buche, die sechste in Österleys Romulus, hier zu höchster Kürze zusammengezogen, so dafs die zu Lafontaine I 6 oder zu Kirchhof VII 23 verzeichneten Bearbeitungen zu vergleichen kaum verlohnt.

23 abc. Das Verbergen der Nester meldet Plinius X 100, das Weglocken des Vogelstellers ders. X I03, die Empfängnis mittels des Geruches X 102. Dagegen stammt aus dem Physiologus die Angabe 23d über den Eierdiebstahl, s. Pitra 353 a 25, noch genauer übereinstimmend Göttw. XXIII S. 578, Cah. u. M. III 248. Die sämtlichen Nachrichten bietet auch Brunetto S. 2 I 4. Die Herleitung des Namens findet sich an keiner der angeführten Stellen; doch kennt sie z. B. Philippe von Thaon: e pur ceo ad tel nun Que pert sa nureture, bei Wright, Pop. Treat. on Science S. 108.

24. Legende von zwei Mönchen, deren einer sich fleischlich verging, worauf der andere, gleiche Schuld vorgebend, die Bufse mit jenem teilte; s. Vie d. anc. pères $\mathrm{N}^{0}$ I (s. dazu über die Berner Legendenhandschrift im Jahrb. f. rom. u. engl. Lit. VIl $404 \mathrm{zu}$ N". 4); ital. bei Cavalca P. III C. I 28 (S. 205). - Ambula cum bonis, Dionys. Cato, Prol. 6. - Cum sanclo sanctus eris . . ct cum perverso perverteris, II: Sam. XXII 26. 27, und Psalm XVII 26. 27. - Qui tetigerit picem u. s. w. Sirach XIII 1.

25. Die erste Angabe mag aus Plinius XXIX 65 stammen: aspides percussos torpore et somno necant. Das übrige ist biblischen Ursprungs; vgl: das Berner Tierbuch bei Cah. u. M. S. 149. Aus beiden Quellen fliefsen auch Brunettos Mitteilungen.

26. Über den Straufs s. Göttw. No. XXIV S. 578 (De Assida), Cah. u. M. III 258, welcher Texte sämtliche Angaben hier wiederholt sind; sie gewährt auch Brunetto Latino 224.

27. Pitra 357 a 26, Cah. u. M. III 263.

29. Omnis vallis exaltabitur u. s. w. Jesaias $\mathrm{XL}$ 4. - Omnis vallis implebitur, Luc. III 5. - Die "andere Stelle" weifs ich nicht 
nachzuweisen. - Super quem requiescet spiritus meus u. s. w. scheint aus Jesaias XI 2 und LXVI 2 zusammengezogen. - Odibilis est corain deo u. s. w. Sirach X 7 .

30. 'Homines sic sunt amandi u. s. w., Augustinus sagt wenigstens Noli propter hominem diligere vitium, nec propler vitium odisse hominem, Sermo XLIX 5 (Migne). Den nämlichen Gedanken spricht Dante im Convivio IV 1 aus.

32. Vgl. Thomas von Aquino, Summa theol., Suppl. Quaest. 81 vel 83: de qualitale resurgentium und Quaest. 83 vel 85: de subtilitate corporum beatorum.

33. Bene autem loqui et male vivere nihil aliud est quam se sua voce damnare. $\mathrm{Ob}$ Augustinus dies sagt, weifs ich nicht. Mit der Kerze, qui s'art Por autrui alumer davant vergleicht der Dichter des Joufroi Z. 3350 den, der ohne Erwiederung liebt, Peire Raimon von Toulouse in Choix III 127 den Dichter, der mit blutendem Herzen zum Ergötzen der Leute singt; dagegen hat, wenigstens nach Wackernagels Auffassung (Ztschr. f. d. A. VI 283) Freidank 7 I,7 in der Kerze den Prediger sehen wollen, der nicht der eigenen Lehre gemäls wandelt; weitere Fälle der Verwendung des Gleichnisses bei mhd. Dichtern verzeichnen Bezzenberger und andere zu der angeführten Stelle.

Odibilis u. s. w. siehe zu 29.

34. se refutat heilst wohl "verleugnet wird".

35. Iratus sum super populum meum u. s. w. Jesaias XLVII 6. I. 5. 11.6.

36. Die Angaben über die Behandlung, die der Rabe seinen Jungen angedeihen lärst, fehlt in den älteren Tierbüchern, findet sich dagegen in einem lateinischen des I 3. Jahrh. bei Cah. u. MI. II 156 , bei Vincentius von Beauvais, in französischen und in provenzalischen Bestiarien, sowie bei Brunetto 2 10. - (Dominus) dat . escam . pullis corvorum invocantibus eum, Psalm CXLVI 9.

37. Ne prospera u. s. w. vgl. Tranquillis rebus, quae sunt adversa, timeto; Rursus in adversis melius sperare memento, Dion. Cato IV 26; Rebus in adversis aninum submittere noli; Spem retine, eb. II 25 .

39. Die sonderbare Fabel ist mir sonst nicht begegnet.

40. Die vierundzwanzigste Fabel des ersten Buches des Phaedrus, deren Bearbeitungen man zu Lafontaine I 3 oder zu Kirchhof VII 53 verzeichnet findet.

4I. Mir nicht bekannt.

42. Die Fabel ist in der vorliegenden Fassung eine eigentümliche Verschmelzung von Elementen derjenigen vom Fuchs und vom Storch (Einladung zum Mahle, das nur für den Wirt geniefsbar ist), der achtundzwanzigsten von Phaedrus' erstem Buche, deren Bearbeitungen die Herausgeber zu Lafontaine I 18 und zu Kirchhof VII 29 aufzählen, und derjenigen von der Maus und vom Frosch 
(tückische Einladung zur Wasserfahrt), die sich im Romulus I 3 (Österley) und an den zu Lafontaine IV I I und zu Kirchhof VII 7 I angeführten Orten findet. Dafs bei dieser Verquickung der Zug von dem rächenden Vogel am Schlusse der zwciten Fabcl weggeblieben ist, erscheint ganz angemessen. Doch findet man denselben in der bei Hervieux II 499 mitgeteilten Fassung (= Marie de France II 68), wo übrigens dem Frosche Wohnung und Speise der Maus wohlgefällt, sie nur den Trunk vermilst.

43. Von dieser Fabel kenne ich keine anderen Bearbeitungen. Die Begegnung des Fuchses mit dem ungeschwänzten Affen im Romulus (Öst.) III I 7 (in afrz. Fassung in Zeitschr. VI 347) verläuft ganz anders. Die Bestrafung des Fuchses durch den Hirsch crinnert an die des Löwen durch das Rols bei Romulus (Öst.) III 2 .

44. Die Fabel steht der dritten im dritten Buche des Romulus (Öst.) nahe ohne ganz mit ihr übereinzustimmen. - Qui autem se exaltaverit, humiliabilur u. s. w. Matth. XXIII I 2.

a. Über bildliche Darstellungen der Monate s. Cte de Grimouard de Saint-Laurent, Guide de l'Art chrétien, T. III S. 499 ff. (Paris, Poitiers I 873), und Strzygowski, die Monatscyclen der byzantinischen Kunst, in Janitscheks Repertorium der Kunstwissenschaft XI 23 ff. (Berlin 1887). Dazu ist zu vergleichen, was der Breviari d'Amor Z. 6564 ff. über den Gegenstand mitteilt. Die Darstellung des Januar ist leicht verständlich, aber, wie es scheint, nicht ganz die gewöhnliche. Der März wird sonst mit einem Gartenmesser abgebildet, und ein solches vermag ich in dem, was er hier hält, nicht zu erkennen. April und Mai haben die Attribute, die sonst die gewöhnlichen zu sein scheinen, vertauscht. Der Juni stimmt zu Matfres Angaben. Der Dreschflegel, den ich in der Hand des Juli zu sehen glaube, ist vielleicht die vom Breviari geforderte Sense. Der November soll nach diesem Säue auf der Eichelweide hüten; hier dagegen wärmt er sich am Feuer, wie es anderwärts der Februar (auch nach Matfre) thut. Das Tier, über welches der Dezember sich geworfen hat, mag ein Schwein sein, wie man es nach dem Breviari zu erwarten hat, und die Unterschrift, die von einem Fuchse redet, als Überschrift zum nächsten Bilde gehören.

c. Eine Anweisung die beim Aufschlagen des Psalters zunächst in die Augen fallenden Buchstaben so zu deuten, dafs sich eine göttliche Offenbarung über zweifelhafte Dinge ergebe, enthält die Handschrift auch Blatt $26 \mathrm{v}^{\circ}$, s. die altvenezianische Übersetzung der. Sprüche des Dionysius Cato, Berlin I 883 S. 86. Eine mit der oben gegebenen ganz gleichartige, lateinisch gefalste Anleitung aus 
den Buchstaben Deutung gehabter Träume zu gewinnen, hat, wie mir Zupitza freundlich nachweist, aus einer Handschrift des 15. Jahrh. Sievers in der Zeitschr. f. deutsches Altertum. I 8, 297 bekannt gcmacht, eine deutsche in dem nämlichen Bande S. 8I Schönbach. Die mhd. Buchstabendeutung aus dem 12. Jahrh., die Steinmeyer eb. 17,84 gedruckt hat, nimmt keinen Bezug auf Träume, kann jedoch der Traumdeutung natürlich ebenfalls dienstbar gemacht werden; gleiches gilt von der vielleicht noch älteren altenglischen, die Sievers eb. 2 I, 189 kennen lehrt. Die von Winnefeld herausgegebenen Sortes Sangallenses (Bonn I 887) haben es nur mit Voraussagung auf Grund der mit Würfeln gewonnenen Zahlen zu thun.

A. TOBLER, 